Cristian Fabiano Guimarães ${ }^{1}$

Rosane Azevedo Neves da Silva ${ }^{1}$

Notes for understanding the problem of "public" health

in the health sector

\title{
Notas para a problematização do coletivo no campo da saúde
}

${ }^{1}$ Departamento de

Psicologia Social e

Institucional, Instituto de

Psicologia, Universidade

Federal do Rio Grande do

Sul. R. Ramiro Barcelos

2600/300 D, Santana. 90035-

003 Porto Alegre RS Brasil.

cfguima@uol.com.br

\begin{abstract}
This paper presents a theoretical review of how the public health concept has been perceived in health practices, based on the problematic field introduced in Italian and Brazilian health reforms, in order to understand the construction of public health and the meanings that this term acquires in the health arena. The main goal is to understand how public health appears in the context of health movements in Italy and Brazil, as well as its movement of variation. In this sense, an attempt is made to identify elements that contribute to the composition of a genealogy of public health. From the investigation of public health practices, the tensions produced by this concept are analyzed, giving visibility to those practices that demonstrate the public health experience as a force in the world of health.
\end{abstract}

Key words Public health, Epistemology, Genealogy
Resumo Este artigo apresenta uma revisão teórica sobre o modo como o coletivo foi sendo problematizado nas práticas de saúde, a partir do campo problemático instaurado pelas reformas sanitárias italiana e brasileira, tendo em vista entender a construção da saúde coletiva e os sentidos que esse termo adquire na saúde. Nosso objetivo principal é entender como o coletivo aparece no contexto dos movimentos sanitários italiano e brasileiro, bem como o seu movimento de variação. Neste sentido, buscamos identificar elementos que contribuam para a composição de uma genealogia do coletivo na saúde. A partir da investigação do coletivo nas práticas de saúde buscamos analisar as tensões produzidas por esse conceito, dando visibilidade àquelas práticas que evidenciam a experiência do coletivo como potência no universo da saúde.

Palavras-chave Saúde coletiva, Epistemologia, Genealogia 


\section{Introdução}

Este artigo apresenta uma revisão teórica sobre o conceito de coletivo no universo da saúde coletiva. Trata-se de um recorte da pesquisa denominada "Variações do Coletivo na Saúde", cujo objetivo é problematizar o modo como o conceito de coletivo é tomado nas práticas de saúde. Neste momento, apresentamos a construção teórica e a estratégia de produção do conhecimento, utilizadas para abordarmos nosso problema de pesquisa. Além disso, partimos de uma análise das reformas sanitárias italiana e brasileira, com a finalidade de entendermos os processos políticos que atravessam e constituem a construção da saúde coletiva.

Há uma diversidade de sentidos que são atribuídos ao termo "reforma sanitária", sendo que entre os projetos de reforma que existiram no mundo, foi a proposta italiana aquela que mais influenciou o pensamento reformista brasileiro. A reforma sanitária italiana se produziu durante os anos sessenta e setenta, culminando em 1978, na consolidação do Servizio Sanitario Nazionale. Tal evento representou um amplo movimento social e cultural, segundo Berlinguer ${ }^{2}$ e Teixeira e Campos ${ }^{3}$, com importantes implicações no plano do saber médico. No caso brasileiro, esse movimento ganha corpo a partir dos anos setenta, sendo que a concretização do projeto político reformista se efetiva com a construção do Sistema Único de Saúde (SUS) em 1988.

A agitação social e cultural da segunda metade do século XX desencadeou movimentos de experimentação que tensionaram a maneira de pensar a medicina social e a saúde pública tanto no cenário italiano, quanto no brasileiro. Sob a influência do espírito reformista italiano, o movimento da reforma sanitária brasileira produziu um novo campo de conhecimentos e de práticas no qual a noção de coletivo foi forjada como objeto $^{4}$, caracterizando, assim, o que se convencionou chamar Saúde coletiva. Propomos colocar em destaque a questão do coletivo na saúde e, ao produzirmos essa provocação, percebemos que a potência desse conceito ainda não foi suficientemente explorada pelos autores da saúde pública em ambos cenários da nossa pesquisa.

No contexto brasileiro, de modo geral, a história da saúde coletiva é contada tomando como eixo a fundação da Associação Brasileira de Saúde coletiva (Abrasco) ou por meio do estudo dos temas de pesquisa mais frequentes, com o intuito de realizar um "balanço" da produção científica na área. Apresentaremos nossa discussão percorrendo um caminho distinto desses dois modos de situar a construção da saúde coletiva: colocaremos em evidência a questão do coletivo e sua relação com a saúde em interface com o campo problemático instaurado pelas reformas sanitárias italiana e brasileira. Ao colocarmos em destaque a noção de coletivo na produção da Saúde coletiva, nosso objetivo é chamar a atenção para o modo como essa questão ganha sentido na saúde, bem como o plano da experiência que ela inaugura, uma vez que "em qualquer percurso e ponto de partida escolhido, ciência e política aparecem como as bases da constituição da saúde [coletiva] como área de conhecimento e de prática social no Brasil [...]. O encontro das duas vocações esteve presente na origem do movimento sanitarista dos anos 1970 e 1980 "'.

Sugerimos que estabelecer as continuidades e as descontinuidades entre as reformas sanitárias italiana e brasileira, na construção da saúde coletiva, pode ser um caminho possível para produzirmos a problematização do conceito de coletivo, identificando as tensões e desdobramentos que tal conceito provoca no plano de conhecimento da saúde e, em especial, no território da saúde pública. Será sobre esse campo problemático que situaremos o conceito de coletivo, chamando atenção para o movimento instituído-instituinte desse objeto no cenário da saúde pública.

\section{A genealogia como estratégia de produção do conhecimento para entender o coletivo na saúde}

Para acompanhar a transformação conceitual da noção de coletivo e sua coprodução no interior das práticas de saúde pública, escolhemos a genealogia como estratégia de produção de conhecimento. A genealogia permite descrever a singularidade dos acontecimentos, possibilitando compreender o campo das práticas sociais e como estas últimas corroboraram para a invenção de determinado objeto.

O método da genealogia conta a história das interpretações, do modo como os objetos são apropriados e os sentidos que lhe são dados, com a finalidade de fazer aparecer relações de força que contribuem para a produção de acontecimentos singulares, de acordo com Dreyfus e Rabinow ${ }^{6}$. Para compreender a genealogia, é preciso diferenciá-la da pesquisa da origem, já que, segundo Foucault ${ }^{7}$, ela não está interessada em encontrar a essência dos objetos, mas evidenciar sistemas heterogêneos que corroboram para a invenção dos objetos, a partir do estudo da proveniência e do contexto de emergência dos mesmos. 
O estudo da proveniência consiste em olhar para o movimento de formação dos objetos, ou seja, para o campo de disputas que desencadeia o seu começo ${ }^{7}$. Ao ser deslocado da sua identidade usual, é possível perceber que o objeto percorre um caminho até sua síntese, sendo que o olhar do pesquisador deve estar atento para a agitação que existe durante esse caminho, com a finalidade de capturar o movimento anterior ao acidente que configura a formação do objeto. Dessa forma, a proveniência diz respeito à apreensão do movimento das forças que concorrem para a formação da identidade do conceito, desconstruindo a ideia de que o mesmo possui uma raiz originária ou uma essência imutável.

A análise da emergência, por sua vez, designa o momento singular em que o confronto das forças marca a insurgência do objeto. Foucault ${ }^{7}$ situa a emergência como a imposição de uma relação que imprime força e duração aos objetos. Ao dominar o objeto, a ação da emergência "fixa um ritual, [...] impõe obrigações e direitos, constitui cuidadosos procedimentos [...], estabelece marcas, grava lembranças nas coisas [...]"’ . Analisar o efeito de dominação que garante o existir concreto para o objeto ou a insurgência de sua identidade, bem como sua força de repetição, é o que permite apreender o sistema de regras no qual este último está enredado.

A análise da proveniência e da emergência coloca em ação o procedimento genealógico. Sua função consiste em explorar como um conceito/ objeto deriva e se desenvolve, bem como os elementos que trabalham para a sua conservação. Ao descrever as forças que entram no jogo da composição do conceito/objeto, a análise genealógica procura desvendar as forças que concorrem na produção do sentido, trazendo para a cena os conflitos que foram subsumidos pela formação atual que triunfou. O esforço dessa estratégia de pesquisa é promover aqueles sentidos relegados ao esquecimento - sentidos menores para problematizá-los, a fim de mostrar que mesmo esquecidos, contribuem para a formação do sentido dos objetos.

Os elementos que compõem a análise da proveniência e da emergência são encontrados na história. A história é importante para a genealogia, sendo fundamental compreender como fazer uso dos dados históricos neste tipo de pesquisa. Se a genealogia recua ao passado, é para isolar os componentes centrais do objeto em análise, decompô-lo, tendo em vista fazer aparecer as forças que compõem a sua existência. Para a genealogia, "a história, com suas intensidades, seus des- falecimentos, seus furores secretos, suas grandes agitações febris, assim como suas síncopes, é o próprio corpo do devir"7. Com a utilização da história, o que se quer é construir um diagnostico do presente para descrever a singularidade dos acontecimentos e mostrar como e em quais circunstâncias os objetos se constituem enquanto tais. Conforme Foucault": "Há toda uma tradição histórica (teológica ou racionalista) que tende a dissolver o acontecimento singular em uma continuidade ideal - movimento teleológico ou encadeamento natural. A história 'efetiva' faz surgir o acontecimento no que ele pode ter de único e agudo. Acontecimento: é preciso entendê-lo não como uma decisão, um tratado, um reino ou uma batalha, mas como uma relação de forças que se inverte, um poder confiscado, um vocabulário retomado e voltado contra seus utilizadores, uma dominação que se enfraquece, se amplia e se envenena, e uma outra que faz sua entrada, mascarada. As forças que estão em jogo na história não obedecem nem a uma destinação, nem a uma mecânica, mas ao acaso da luta"7.

Ao explicitar a perspectiva de história que contribui para a análise genealógica, Foucault ${ }^{7,8}$ realiza uma crítica ao modo de interpretar a história como uma ordenação natural do mundo e, ao mesmo tempo, rejeita a tese que sustenta que a história tem um sentido oculto a ser revelado. A história deve fornecer elementos para compreender o acontecimento. Dessa forma, é possível descrever os movimentos de transformação dos objetos e o jogo de forças que existe entre eventos da história muitas vezes distintos uns dos outros.

A história tradicionalmente contada da Saúde coletiva, vista à luz da evolução de um processo histórico, pressupõe a superação da medicina social e da saúde pública, por exemplo, em direção a um estado do conhecimento mais avançado. Nesse sentido, a estratégia genealógica busca romper com a visão progressista, objetiva e totalizante da história da Saúde coletiva, sem adentrar numa perspectiva subjetivista, pois ela constrói o conhecimento colocando em análise as práticas concretas que constituem os objetos. O desafio metodológico da análise histórica para a genealogia consiste, portanto, em superar a visão linear e totalizante da história, para descer ao nível das lutas, ou seja, para apreender a batalha de construção do projeto do coletivo no interior da saúde coletiva. Portanto, ao colocar em questão os conceitos, é possível identificar a qual necessidade eles respondem. Com isso, ao interrogarmos o coletivo no sistema de pensamento da saúde e sua construção/inscrição nos contextos 
históricos e sociais dos movimentos de reforma sanitária italiana e brasileira, estamos problematizando a experiência do coletivo no universo da saúde pública, de modo que os dados gerados contribuem para avançarmos na compreensão da invenção da Saúde coletiva, bem como das práticas desenvolvidas nesse campo.

\section{A noção de variação como potência: o instituído e o instituinte na construção da saúde coletiva}

Muitos autores brasileiros discutiram a construção da Saúde coletiva, sendo que existe uma vasta literatura sobre esse assunto ${ }^{5,9-21}$. Estes autores envidaram esforços para apresentar o percurso histórico da saúde coletiva, com a finalidade de discutir o seu surgimento. Vamos brevemente reconstruir esse percurso para discutir os principais elementos que marcaram a singularidade do contexto histórico de surgimento dessa disciplina. Faremos esse percurso destacando o modo como o coletivo foi sendo forjado no campo problemático instaurado pelas reformas sanitárias, a partir da segunda metade no século XX na Itália e no Brasil, utilizando como estratégia um olhar genealógico.

Podemos compreender a saúde coletiva pelo menos de duas maneiras: como um projeto de construção de um saber que opera no campo da saúde, e também como um programa que contempla uma especificidade no interior desse campo. Quando nos referirmos à saúde coletiva como um projeto, estaremos fazendo referência ao saber inventivo construído ao longo dos anos setenta, tomando-o no momento em que ele ainda não estaria "enclausurado" num corpo disciplinar. Em tal momento, a ênfase recai sobre o processo e a potência que habita a produção desse saber, ao passo que na saúde coletiva entendida como um programa observa-se um saber constituído que funciona com uma identidade bem estabelecida. Para Negri ${ }^{22}$, o crescimento da potência tem como efeito exacerbar a desordem, sendo que esse movimento é condição de possibilidade para a produção do novo em qualquer dimensão da vida. Dessa forma, é possível percebermos que a agitação produzida nos anos sessenta e setenta pelas reformas sanitárias desencadeou a construção de processos relacionais e criativos que contribuíram para tensionar a maneira de pensar a medicina social e a saúde pública tanto no cenário italiano, quanto no brasileiro.

No Brasil, a produção de novas leituras sobre a realidade sanitária no interior dos Depar- tamentos de Medicina Preventiva e Social de algumas Faculdades de Medicina desencadeou o processo denominado de "crise da saúde pública". Ou seja, com o incremento de novas perspectivas teóricas no campo da saúde, a maneira de pensar a medicina social e a saúde pública foi colocada em discussão ${ }^{23-25}$, constituindo as condições de possibilidade para a invenção de um novo saber.

Para avançarmos na análise da construção da saúde coletiva, prestemos atenção no modo como Cohn ${ }^{1}$ apresenta essa discussão. Conforme a autora: "[...] a área de Medicina Social passa a ser denominada de saúde coletiva. Buscava-se assim suplantar, no Brasil, a histórica distinção entre Medicina Social e Saúde Pública, em que a primeira muitas vezes passava a ameaçar esta, área tradicional de enfoque da saúde no âmbito coletivo. [...] Ao substituir-se "Medicina" por "Saúde" amplia-se o objeto, tornando-o mais abrangente, o que passa a exigir uma nova delimitação do campo. E, ao substituir-se o social pelo coletivo, torna-se este mais inespecífico, exigindo que seja rastreado em sua totalidade. Mas ao mesmo tempo requer da saúde coletiva que incorpore a produção clássica da Saúde Pública, agora no novo entendimento da relação entre o biológico e o social [...]" ${ }^{\prime}$.

Sob a ótica de $\mathrm{Cohn}^{1}$, é possível perceber que a noção de saúde coletiva vem substituir a noção de medicina social no contexto brasileiro e, ao mesmo tempo, integrar a saúde pública ao plano do conhecimento estruturado por esse novo saber. Entretanto, Costa $^{14}$ afirmou que não podemos considerar a saúde coletiva como uma simples substituição do termo medicina social, ou mesmo pela justaposição de fragmentos de outras disciplinas, uma vez que sua construção foi acompanhada pela produção de novas leituras da realidade sanitária que ultrapassam os limites das disciplinas que povoavam o campo da saúde. Portanto, a construção dessa disciplina não pode ser pensada enquanto um processo natural de evolução do conceito de saúde pública, pois sua construção encontrará sentido num contexto histórico específico e no jogo de lutas pela construção da democracia no Brasil. Do mesmo modo, ela não pode ser pensada como simples substituição de termos, uma vez que tanto o conceito de saúde quanto o de coletivo serão colocados em discussão.

Cohn ${ }^{1}$ define o coletivo como "inespecífico", sendo que essa dimensão de inespecificidade é uma característica importante para entendermos a saúde coletiva como um projeto. Ao defini-lo dessa forma, a autora ${ }^{1}$ não explora o conceito de 
coletivo na originalidade com a qual ele aparece no processo de construção da saúde coletiva como um projeto. A crise na saúde pública foi acompanhada pela produção de novas leituras sobre a realidade sanitária brasileira, sob um plano de produção comum em ressonância com o movimento reformista, onde o conceito de coletivo vai operar como potência de criação de novos sentidos para o campo da saúde.

Portanto, a operação do coletivo como potência e espaço de produção de novos sentidos é central na construção da saúde coletiva como projeto. Tomado desta perspectiva, o coletivo não se reduz à ideia de conjunto ou agrupamento. $\mathrm{O}$ coletivo, neste caso, é entendido como "potência constituinte"22, "movimento instituinte"26. De agora em diante, adotaremos esse modo de compreender o coletivo, grifando-o em negrito, para diferenciá-lo do coletivo institucionalizado, que será grifado em itálico. O coletivo institucionalizado diz respeito aos esforços da saúde coletiva para produzir uma identidade para esse conceito e limitar a experiência do coletivo enquanto base expansiva de produção de resistência, enclausurando sua força em formas de representação. Quando esse termo aparecer nas citações de autores, ele será marcado no texto de forma simples, tendo em vista manter a fidedignidade com o texto do autor citado. As diferentes maneiras de grifar o coletivo ao longo deste texto buscarão chamar a atenção do leitor para as vibrações desse termo no campo da saúde, além de nos ajudar a discutir a sustentar a tese de que existem variações do coletivo na saúde.

Ao entendermos o coletivo enquanto plano de produção do comum buscamos colocar em evidência uma dimensão ético-política que atravessa a construção da saúde coletiva e a produção dos movimentos sanitários italiano e brasileiro, sendo que tal dimensão é entendida como capacidade de desencadear o princípio instituinte como eixo de produção de novos projetos no campo da saúde. Quando Cohn ${ }^{1}$ situa o coletivo como inespecífico, é possível identificarmos a operação da potência em ato e, ao mesmo tempo, afirmar que esse momento diz respeito à construção da saúde coletiva como um projeto.

A noção de coletivo sustenta uma tensão no campo da saúde, uma vez que sua identidade ainda não está caracterizada. A inespecificidade do coletivo, ao contrário de significar um vazio de sentido, pode ser compreendida como um espaço carregado de potência, uma vez que será sobre esse plano que diferentes forças disputam e cooperam para a construção de um projeto comum.
Sobre esse espaço aberto foi possível desenhar diferentes leituras sobre a realidade sanitária; sobre ele se inscreveu o saber e o agir na produção de um novo projeto para a saúde, embora Cohn ${ }^{1}$ não veja dessa maneira.

Negrii $^{22}$ explica a produção do comum como relação de singularidades que cooperam. O comum é força não identitária que se constitui como relação, pois desencadeia o aumento da capacidade de ação dos sujeitos. O movimento instituinte que se instaurou na construção da saúde coletiva como projeto é processo de produção do comum, uma vez que são forjados espaços reais de produção e resistências. A resistência é a expressão de fundação de um espaço comum onde opera a potência, entendida como "ato de escolha, a determinação pontual que abre um horizonte, 0 dispositivo radical de algo que ainda não existe"22.

A dimensão da inespecificidade do coletivo pode, portanto, ser entendida como o momento de operação do coletivo como movimento instituinte em direção à construção de um novo projeto de conhecimento para o campo da saúde. Só será possível afirmar a existência de uma inespecificidade se o movimento instituinte desencadeado não for colocado em questão, conforme já salientamos anteriormente, pois o modo de "estar junto" e "inventar com" disparado pelo coletivo provocou a deformação no plano do conhecimento da medicina social e da saúde pública brasileiras. A singularidade desse momento pode ser caracterizada como um acontecimento na história da saúde no país, uma vez que convoca uma inversão de forças que tensiona a reorganização do conhecimento e desencadeia a produção de novas práticas no campo da saúde.

Entretanto Cohn ${ }^{1}$ já anunciava o espírito que animaria os teóricos da saúde coletiva, antecipando a transformação desse saber-projeto em programa: o coletivo deve ser "rastreado na sua totalidade"1, dizia a autora. Nesse enunciado é possível perceber que ao mesmo tempo em que se produzia uma operação do coletivo no campo da saúde, também se iniciava o movimento de institucionalização da sua potência. Vamos acompanhar tal processo, sem perder de vista que ele se relaciona tanto com um movimento do saber, quanto com a produção de uma prática social que encontra sua materialidade nos movimentos reformistas italiano e brasileiro, pois o coletivo vai ser trabalhado tanto no plano do conhecimento quanto no da prática política.

Pelo menos duas direções de análise podem ser construídas para entender o coletivo na saúde coletiva, que se diferenciam em função do des- 
taque que é dado a um ou outro elemento que compõem o termo "saúde coletiva": uma direção que busca enfatizar o conceito de coletivo ${ }^{4,18,20} \mathrm{e}$ a outra que focaliza a discussão na ampliação do objeto saúde ${ }^{27-30}$. Realizamos essa distinção para melhor apresentarmos como o coletivo vai ser capturado. Portanto, é preciso fazer a ressalva de que tal distinção em duas direções de análise apresenta caráter didático, pois a ampliação do conceito de saúde provoca uma torção no conceito de coletivo, e vice-versa.

Começaremos pela segunda direção, qual seja, a ampliação do conceito de saúde, sendo que ela se produz em sintonia com o alargamento do campo sanitário e, consequentemente, do campo de intervenção da saúde. Na década de setenta, os limites da perspectiva funcionalista presentes nas ciências sociais em saúde são questionados, e uma proposta de marco teórico alternativo, com foco na análise da mudança, nas contradições internas do sistema de saúde e nas relações específicas e estruturais da organização da prática médica, ganha espaço no campo da saúde. As discussões no interior do campo das ciências sociais em saúde garantiram condições de viabilidade para a construção de um novo conceito de saúde ${ }^{11}$. Costa $^{14}$, por exemplo, destaca que a existência de um espaço para pensar o processo saúde-doença de forma mais abrangente, tanto no âmbito da investigação biomédica, quanto no interior da educação sanitária, foi possível especialmente com a aplicação de novas teorias no campo da saúde.

A substituição do termo medicina pela noção de saúde implicou uma transformação desse conceito, tendo em vista ultrapassar a definição de saúde como ausência de doença, na qual se produz uma leitura do processo saúde-doença para além do modelo biomédico: "A concepção de saúde coletiva, [...] se constituiu através da crítica sistemática do universalismo naturalista do saber médico. Seu postulado fundamental afirma que a problemática da saúde é mais abrangente e complexa que a leitura realizada pela medicina. A partir da década de 1920, as Ciências Humanas começaram a se introduzir no território da saúde e, de modo cada vez mais enfático, contribuíram com a problematização de categorias como normal, anormal, patológico, afirmando que nelas haveria valores. Por isso, a instituição dessa problemática através da medicina produziu necessariamente uma série de efeitos nos planos político e social. O discurso da saúde coletiva, em suma, pretende ser uma leitura crítica desse projeto médico-naturalista, estabelecido historicamente com o advento da sociedade industrial" ${ }^{30}$.
O campo problemático aberto pelo coletivo suscitou no campo da saúde brasileiro a transformação no conceito de saúde, que foi forjado a partir da crítica sistemática do universalismo naturalista produzido pelo saber médico e com a relativização do modelo biológico na compreensão do processo saúde-doença existente. Para Bir$\operatorname{man}^{30}$ " [...] a noção de saúde coletiva representa uma inflexão decisiva para o conceito de saúde. [...] De fato, o campo teórico da saúde coletiva representa uma ruptura com a concepção de saúde pública, ao negar que os discursos biológicos detenham o monopólio do campo da saúde”.

À inflexão produzida no conceito de saúde corresponde a afirmação do coletivo enquanto potência, cujo efeito foi a ampliação do campo sanitário, com o consequente alargamento das questões a serem tomadas como objeto da saúde pública e do seu campo de intervenção. Para Birman $^{31}$, a saúde pública toma como objeto de práticas um campo sanitário que teve de ser reinventado com a saúde coletiva. Com a ampliação do conceito de saúde, também novos modelos explicativos e metodologias foram introduzidas no campo. Temos, portanto, um elemento importante que corroborou com a invenção da saúde coletiva: a mudança no conceito de saúde. Com isso, o universo de intervenção da saúde se expandiu e outras disciplinas passaram a participar da discussão sobre a saúde pública. Paim e Almeida Filho ${ }^{15}$ explicitam de forma bastante objetiva esse aspecto: “[...] el desafío más crucial en este momento de discusión de las bases epistemológicas de la salud pública és justamente la cuestión del objeto salud [...], abriéndose la ciencia a la possibilidad de la emergencia o sea, el engendramiento de lo radicalmente nuevo".

Para a saúde coletiva, o processo saúde-doença é determinado social e historicamente. A noção de determinação social do processo saúde-doença é uma novidade introduzida no campo da saúde com a ampliação do conceito de saúde. Para Laurell ${ }^{132}$ o conceito de determinação social diz respeito à construção do processo saúde-doença como fenômeno coletivo e fato social, uma vez que esse processo se manifesta de forma mais clara no nível da coletividade do que no indivíduo. Portanto, a compreensão do caráter histórico e social do processo saúde-doença toma como objeto o grupo, sendo que este último "não adquire relevância por ser constituído por muitos indivíduos"32, mas porque permite apreender a dimensão social do conjunto de indivíduos que deixam de ser entendidos como entes biológicos justapostos. Com isso, Laurell ${ }^{32}$ destaca que não são especificamen- 
te os grupos enquanto tais o objeto de estudo dessa nova concepção, mas o processo saúde-doença dos indivíduos agrupados. A partir da seleção do grupo com base em suas características sociais, $\mathrm{o}$ estudo concreto se realizaria nos indivíduos que o compõem. Com isso, seria possível compreender o processo saúde-doença na sua historicidade, ou seja, como socialmente determinado. $\mathrm{O}$ movimento de submissão da normalidade biológica ao momento histórico deveria ser realizado com a utilização de metodologias sociais e biológicas num processo de pesquisa único, sendo que a interpretação dos dados não se daria em função de cada caso individual, mas do conjunto de indivíduos do grupo.

Com Laurell ${ }^{32}$ podemos identificar o esforço para ligar a discussão sobre a ampliação do conceito de saúde, o processo saúde-doença e sua historicidade à coletividade, no qual é possível percebermos que o coletivo aparece como grupo composto de um conjunto de indivíduos, em que cada um deve ser entendido individualmente e em relação com o grupo. Ao mesmo tempo em que realiza um recorte do coletivo, coloca a questão do grupo-população como sinônimo de coletivo, afirmando a dicotomia entre indivíduo e grupo, uma vez que a autora defende que a centralidade da leitura do processo saúde-doença se situa no nível individual.

Embora possamos perceber que um conjunto de esforços foram produzidos no sentido de situar a construção da saúde coletiva a partir da ampliação do conceito de saúde, do alargamento do campo sanitário e da introdução do conceito de determinação, tal perspectiva aborda apenas uma dimensão para compreendermos o coletivo no campo da saúde. Tal questão sugere a necessidade de avançar no desenvolvimento de discussões epistemológicas e metodológicas. Fleury ${ }^{24}$ chama a atenção para essa questão: "[...] apesar da grande utilização desse modelo de explicação nas políticas de saúde, e, por certo, de sua grande utilidade como instrumental analítico, há que se reconhecer a necessidade do desenvolvimento de estudos epistemológicos que busquem desenvolver a noção de determinação [...]".

Outros teóricos da saúde coletiva discutiram a especificidade do coletivo. Para Felipe ${ }^{17}$, a "especialidade do novo campo estaria dada pelo seu objeto: o coletivo". Este autor sinalizou que as práticas não guardavam homogeneidade na definição deste termo, embora existisse consenso quanto à necessidade de tomá-lo em suas manifestações histórico-concretas. Estamos adentrando na segunda dimensão apontada anterior- mente, cuja ênfase da definição da saúde coletiva como programa recai sobre a discussão do coletivo enquanto construção histórica.

Merhy ${ }^{18}$ afirma que o objeto de ação da saúde pública é o coletivo, destacando que esta categoria é entendida a partir de diferentes concepções, o que permite identificar uma variedade de formas de interpretação desse conceito no campo da saúde. Dessa forma, o autor quer apontar as diferenças que existem na concepção de coletivo no território da saúde pública e na saúde coletiva. A multiplicidade de concepções para a noção de coletivo leva à existência de uma heterogeneidade de práticas concretas que colocam em atividade ações que estariam mais próximas ou não da perspectiva introduzida pelo pensamento da saúde coletiva. Identificar como esse conceito é entendido ajuda a compreender o universo das práticas produzidas no território da saúde pública brasileira, porque, conforme o autor, "a concepção que se elabora sobre o coletivo possibilita a criação de diferentes caminhos na compreensão das práticas de saúde"18.

Para Merhy ${ }^{18}$ existem pelo menos três maneiras de compreender o coletivo no cenário da saúde: a concepção que toma esse objeto como exterior aos indivíduos e representado como meio externo; outra que toma esse objeto como o social ou sociedade, embora ainda em relação de exterioridade aos indivíduos; e, por fim, a concepção que entende o coletivo como campo estruturado de práticas sociais ou totalidade das práticas sanitárias tomadas enquanto construção histórica. A primeira forma de entender o coletivo convoca as ciências naturais e os métodos da ciência positiva para abordar esse objeto. Esse modo de compreender o coletivo está presente nas práticas sanitárias que buscam intervir sobre o meio ambiente ou sobre o meio e o agente etiológico de determinada doença. Dessa forma: “[...] as práticas centradas no individual e no biológico, como as da medicina, quando tornadas em instrumentos de intervenção do coletivo, passam a compor o conjunto das práticas coletivas de saúde. Isto é, quando o cuidado médico é visto como medida sanitária, ele visa o coletivo que os indivíduos (enquanto coleções) expressam"18.

Quando o coletivo assume o estatuto de social, sendo que a noção de social mantém uma relação de exterioridade e de oposição ao individual, são as ciências sociais que se apropriam desse objeto, utilizando métodos oriundos desse campo do conhecimento. Nesta perspectiva, mantém-se a base metodológica oriunda das ciências naturais para a abordagem do social entendido como so- 
ciedade, sendo esse o segundo modo de compreender o coletivo.

Por fim, ao ser compreendido como campo estruturado de práticas sociais e representado pela totalidade das práticas sanitárias, a leitura do coletivo seria construída a partir do modelo oriundo do materialismo histórico e as práticas desenvolvidas no campo da saúde compreendidas como produção da história. Nessa concepção de coletivo a noção de social continua sendo importante, sendo que este objeto não está em relação de exterioridade com a produção das práticas sanitárias. Conforme Merhy ${ }^{18}$ : "a historicidade dos objetivos destas práticas e os objetos e instrumentos a elas correspondentes, [são compreendidos] como constituintes das práticas sociais, onde esta prática se efetiva. Assim sendo, elas se tornam inteligíveis enquanto práticas sociais estruturadas, constitutivas de uma estrutura social determinada".

Ao tomar o coletivo como "práticas constitutivas", Merhy ${ }^{18}$ se aproxima da nossa questão de estudo. Entretanto, é importante destacar que este autor também não está preocupado em problematizar o coletivo no campo da saúde, mas apresentar as diferentes identidades que esse objeto assume. Merhy ${ }^{18}$ avança, embora sem colocar em discussão o movimento instituinte do coletivo e a consequente produção comum da deformação das estruturas sociais que ele opera, sendo que sua ênfase recai sobre a estrutura social constituída, ou seja, sobre o grupo-sociedade como totalidade.

$\mathrm{Na}$ transição entre um coletivo enquanto potência para o coletivo institucionalizado na saúde coletiva e, ao mesmo tempo, o movimento de transformação deste saber enquanto projeto num saber-programa, podemos observar que o efeito mais imediato é a tendência à totalização da saúde coletiva como única experiência possível no campo da saúde, uma vez que ela abrange a totalidade do coletivo. Como sugere Campos ${ }^{10}$ : "Para alguns, a saúde coletiva se constitui numa espécie de metadiscurso supostamente capaz de criticar e reconstruir saberes e processos concretos de produção de saúde. Nesse sentido, ela forneceria meta-explicações autossuficientes sobre a tríade saúde, doença e intervenção. Por outro lado, seu discurso constitutivo tenderia a hipervalorizar a determinação social dos processos saúde/doença, desqualificando os fatores de ordem subjetiva e biológica”.

A partir dessa reflexão é possível perceber que na construção da saúde coletiva o coletivo se confunde com grupo, população ou sociedade, sen- do que o conjunto de consensos que começam a aparecer em torno desse objeto tende cada vez mais a enclausurar o coletivo. Tal movimento é simultâneo à construção da identidade da saúde coletiva e sua transformação em programa. Esses consensos levaram à compreensão de que não era o indivíduo enquanto corpo biológico o objeto da saúde coletiva, mas os sujeitos sociais socialmente construídos na sua relação com o processo saúde-doença ${ }^{27}$.

No plano do movimento reformista brasileiro a mutação do coletivo como potência para o coletivo institucionalizado também se faz sentir. Essa operação fornecerá a base para a saúde coletiva organizar a dimensão da prática, pois será o coletivo entendido como sociedade que estará em jogo nesse cenário. Sabemos que a reforma brasileira foi influenciada pelo pensamento reformista italiano. Berlinguer ${ }^{33}$ afirmou que, para a concretização da reforma sanitária italiana, deveria ser colocado em primeiro plano a ampliação da luta pela saúde, evidenciando que esse processo é de caráter coletivo. Este autor explora um contexto no qual o movimento operário italiano forjava uma noção de coletivo enquanto potência. Os textos de Berlinguer ${ }^{2,33}$ divulgados no Brasil colocam ênfase no trabalho da sociedade civil organizada para a concretização do movimento reformista, sendo que este aspecto foi um elemento importante para o processo de construção da reforma sanitária brasileira. Com isso é possível percebermos que uma noção de coletivo se produziu no Brasil, sob a influência do pensamento italiano e do modo como Berlinguer ${ }^{2,33}$ compreendeu esse processo.

Como afirmamos anteriormente, a saúde coletiva como um projeto no plano do coletivo foi desencadeada pelo campo problemático introduzido pelas reformas sanitárias italiana e brasileira. Portanto, é no campo problemático instaurado pela reforma sanitária que será possível identificar a saúde coletiva como um projeto comum e, ao mesmo tempo, situar uma experiência do coletivo. Ao se encontrar com a reforma sanitária brasileira, a construção da saúde coletiva como um projeto localiza o coletivo como sociedade e o limite para a sua produção como potência. Dado esse encontro, mais uma vez é possível perceber que o problema do coletivo como potência foi sendo marginalizado também no interior do movimento reformista.

Entretanto, podemos perceber que a leitura que Berlinguer ${ }^{2,33}$ realiza sobre a produção italiana no contexto da reforma sanitária não reflete de maneira homogênea a agitação produzida no ce- 
nário italiano nesse período. Guattari ${ }^{34}$ contribui para colocarmos em questão a noção de coletivo instituída pelo movimento reformista brasileiro, uma vez que este autor opera numa perspectiva teórica na qual importa compreender a micropolítica das relações que foram produzidas no cenário italiano. Para Guattari ${ }^{34}$, o movimento, no início da segunda metade do século XX, na Itália, corrompeu a crença na valorização dos movimentos sociais organizados e na sociedade civil. O movimento operário italiano se caracterizou por operar uma crise no sentido atribuído ao termo potere operaio, que se desloca de uma concepção homogênea que localizava nos partidos políticos ou nas instituições da sociedade civil o núcleo de representação e exercício desse poder, para se dispersar em movimentos de revolta em diferentes níveis de autonomia. Com isso, criam-se nos anos setenta círculos políticos-culturais como o Gatto Selvaggio e a Rádio Alice, em Bolonha, por exemplo, que não estão ligados a equipamentos burocráticos de qualquer espécie.

Para Guattari ${ }^{34}$, o movimento operário italiano reconhece que os intelectuais orgânicos são burocratas da teoria, identificando que a condição de possibilidade para uma prática tornar-se subversiva é o seu caráter coletivo. O modo como este autor compreende o movimento produzido no cenário italiano no período de institucionalização do Servizio Sanitario Nazionale sugere um contexto de agitação política que tomava como eixo estruturante uma noção de coletivo que não é problematizada na literatura disponível no Brasil sobre a reforma sanitária italiana, sendo que o modo como essa experiência penetrou na medicina social daquele país merece ser aprofundada para avançarmos na discussão proposta pela nossa pesquisa. $\mathrm{O}$ coletivo forjado pelo movimento operário italiano, da maneira como Guattari ${ }^{34}$ nos ajuda a compreender, remete nosso olhar para o conjunto de práticas e o campo problemático instaurado na Itália no âmbito da saúde com o movimento operário italiano, apontando um território a ser explorado, para pensarmos a saúde coletiva no cenário brasileiro.

Ao definirem o coletivo como um conjunto de práticas de saúde que são estudadas à luz de diferentes concepções teóricas e metodológicas, os teóricos da saúde coletiva avançam na organização desse saber como um programa. Nesse sentido, Teixeira ${ }^{20}$ afirma que o conjunto estruturado das relações sociais de um tipo de prática médica pode ser tomado como evidência do coletivo, pois conduz um deslocamento da ênfase do processo saúde-doença - na qual a questão do coletivo como sujeito social é problemática - para a análise das práticas de saúde tomadas sob diferentes perspectivas teóricas e metodológicas. A questão do coletivo é problemática porque é justamente a possibilidade de sustentar a tensão e de instaurar a crise como força de resistência que libera a potência de criação e a construção de novos projetos no campo da saúde.

Até este momento, tentamos evidenciar que no campo da saúde existe uma batalha na qual o coletivo como potência é capturado e transformado em coletivo instituído pela saúde coletiva. Apresentamos as duas dimensões que foram destacadas pelos autores como fundamentais para compreender a saúde coletiva, ou seja, a ampliação do conceito de saúde e a ênfase na definição do coletivo. Com isso, provocamos o leitor a percorrer conosco o caminho que analisa como o coletivo vai sendo capturado com a construção da identidade da saúde coletiva, ou seja, sua consolidação como um programa.

\section{A cartografia do coletivo como potência na saúde: um velho/novo problema de pesquisa para a saúde coletiva}

Neste ponto, é possível afirmarmos que nossa pesquisa procura destacar a continuidade/ descontinuidade da dimensão "subversiva" do coletivo nas reformas italiana e brasileira, tendo em vista verificar em que práticas de saúde esse movimento instituinte e de produção do comum pode de sustentar. Para situar nossa discussão, problematizamos a construção da saúde coletiva, buscando evidenciar os diferentes sinônimos utilizados para caracterizar o coletivo: população, grupo ou sociedade civil.

Sob o plano de análise que desenhamos até o momento é possível perceber que a noção de variação carrega um duplo sentido: ela é processo infinito de potência e produção do comum e sua captura em formas instituídas. A noção de variação foi escolhida porque ajuda a chamar a atenção para a operação do coletivo, evidenciar suas formas instituídas e provocar a crise no coletivo, dando passagem à potência. Produção do comum, captura/representação do instituinte e liberação da potência são três variações possíveis do objeto que estamos estudando na saúde.

Ora, se o coletivo pudesse ser representado pelos seus sinônimos apenas, não haveria necessidade de pensarmos numa saúde coletiva, uma vez que desde muito tempo os conceitos de população e sociedade são utilizados no campo da saúde $^{25,35-37}$. Se assim fosse, esta última poderia 
ser chamada de saúde da população ou saúde da sociedade. É preciso levantar esse questionamento para destacar/analisar outra dimensão do coletivo e suas formas de expressão no cotidiano das práticas de saúde.

Do mesmo modo, torna-se necessário explorar os conceitos de população e sociedade, tendo em vista mostrar a impossibilidade de considerar essas noções de coletivo na saúde coletiva e, ao mesmo tempo, fazer aparecer a vibração do coletivo no campo da saúde, chamando a atenção para uma dimensão pouco explorada no campo problemático introduzido pelas reformas sanitárias italiana e brasileira, bem como na construção da saúde coletiva. Ao problematizarmos o conceito de coletivo, é possível abrir espaço para a dimensão instituinte das práticas no universo da saúde, para além das suas variações habituais. Resgatar o cenário italiano justifica-se, uma vez que com o movimento operário italiano o coletivo funcionava como plano instituinte, força de potência e criação, tensionando o instituído e abrindo um novo campo de possibilidades para entender a saúde coletiva.

Ao colocarmos em discussão as duas maneiras de compreender a saúde coletiva - como projeto e como programa, estamos buscando evidenciar como a produção de um conjunto de saberes e de práticas trabalham o coletivo e limitam a sua potência no cenário brasileiro, a fim de identificar uma geopolítica do conceito de saúde coletiva. É possível perceber que o coletivo é plano instituinte (comum) e forma instituída (coletivo). A partir do plano que foi desenhado, podemos perguntar: o que é e quais formas de expressão do coletivo como potência existem no campo da saúde? A partir da investigação do coletivo no contexto mais geral da medicina social na Itália e da saúde coletiva no Brasil, procuramos analisar as tensões produzidas, tomando como ponto de partida da nossa cartografia o olhar genealógico sobre as práticas dos movimentos reformistas nesses dois países. Como pudemos perceber, o coletivo produziu uma agitação no campo da saúde; resgatar esse processo a partir das reformas sanitárias é uma maneira de sustentar a experiência do coletivo na saúde.

Ao tomarmos a variação como movimento da repetição que invoca a forma do idêntico do conceito $($ coletivo $=$ população e coletivo $=$ grupo ou sociedade civil), estamos apresentando os sinônimos do coletivo, ou seja, mostrando como esse objeto varia no plano da representação. Dessa forma, operamos com uma noção de coletivo sob o registro da macropolítica, do instituído ou do poder constituído, de modo que sob esse registro é possível que as práticas desenvolvidas no contexto da saúde coletiva se estruturem sob uma falsa sensação de novidade, transformando a noção de coletivo em clichê. Na saúde, o coletivo não pode ser confundido com população, grupo ou sociedade, sob o risco de deixar em suspenso a potência que esse conceito carrega e sua capacidade de afirmar a diferença.

A construção que fizemos até aqui mostrou o tensionamento existente entre instituinte e instituído na composição da saúde coletiva, tomando como campo problemático as reformas sanitárias italiana e brasileira. Nossa hipótese é a de que a problemática central dos movimentos reformistas italiano e brasileiro foi sustentar a potência enquanto produção do comum, sendo que pensar práticas coletivas de saúde, a partir da ruptura que os movimentos sanitários introduzem na saúde pública, significa permitir a expressão do coletivo. Caso estejamos no caminho certo, é possível arriscar que os movimentos reformistas introduziram uma diferença que ainda não foi levada ao limite pela medicina social italiana ou pela saúde coletiva. Esta diferença pode ter sido sucumbida em vista da institucionalização do $c o$ letivo na saúde. Nossa cartografia deverá permitir aprofundar tais questões, em direção à construção de práticas cooperativas, criativas e inovadoras no cenário da saúde pública.

Ao problematizarmos o coletivo, tomando como analisador o território das lutas produzidas nos contextos reformistas da Itália e do Brasil, queremos evidenciar a descontinuidade provocada no plano do saber que tais movimentos produziram e sustentar a potência do coletivo como movimento de criação e resistência na saúde. Acreditamos que seja possível - e necessário - sustentar o princípio instituinte do coletivo na saúde, uma vez que ele é condição de possibilidade para mudanças concretas, conforme destacado anteriormente. Assim, "Quando se diz que 'a reforma sanitária corre o risco de falir porque a medicina italiana é de má qualidade', constata-se um fato, percebe-se um perigo, mas se faz uma inversão lógica. De fato, o ponto de partida deveria ser: 'a medicina é de má qualidade porque a reforma sanitária foi até agora impedida”33.

$\mathrm{Na}$ mesma linha de raciocínio, Campos ${ }^{9}$ pergunta com relação ao contexto brasileiro: "quem seriam os sujeitos coletivos capazes de fazer avançar a reforma incompleta?" . Ao problematizarmos o coletivo no campo da saúde, com o objetivo de compreender que variações são produzidas, nosso problema de pesquisa coloca em 
discussão uma questão ético-política, pois nos dois países que são foco do nosso estudo, o que se tem é uma reforma sanitária que não se fecha seja na institucionalização do Servizio Sanitario Nazionale ou do Sistema Único de Saúde (SUS), e tampouco na institucionalização da saúde coletiva como no caso brasileiro. Entendemos que a reforma sanitária é processo contínuo e está inserida na realidade cotidiana, pois mesmo com a institucionalização dos projetos reformistas sua transformação em programas - novos desafios são colocados. Situar o coletivo nesse cenário para compreender como ele varia e os tensionamentos que produz no plano do conhecimento pode nos ajudar a entender quais impasses e quais possibilidades existem hoje para fazer a reforma sanitária avançar e entender quem são os sujeitos coletivos desse processo.

\section{Colaboradores}

CF Guimarães e RAN Silva participaram igualmente de todas as etapas de elaboração do artigo. 
Referências

1. Cohn A. Caminhos da Reforma Sanitária. Lua Nova 1989; 19:123-140.

2. Berlinguer G. Medicina e política. $3^{a}$ ed. São Paulo: Hucitec; 1987.

3. Teixeira SF, Campos GWS. Reforma Sanitária: Itália e Brasil. São Paulo: Hucitec; 1988. p. 1-106.

4. Felipe JS. Uma avaliação da produção teórico-científica da medicina social no Brasil. Saúde em Debate 1989; 27:59-66.

5. Lima NT, Santana JP, organizadores. Saúde coletiva como compromisso: a trajetória da Abrasco. Rio de Janeiro: Fiocruz, Abrasco; 2006.

6. Dreyfus HL, Rabinow P. Michel Foucault, uma trajetória filosófica: para além do estruturalismo e da hermenêutica. 2a ed. Rio de Janeiro: Forense Universitária; 2010.

7. Foucault M. Nietzsche, a genealogia, a história. In: Foucault M. Ditos \& Escritos II: arqueologia das ciências e história dos sistemas de pensamento. Rio de Janeiro: Forense Universitária; 2005. p. 260-281.

8. Foucault M. Sobre as maneira de escrever a história. In: Foucault M. Ditos \& Escritos II: arqueologia das ciências e história dos sistemas de pensamento. Rio de Janeiro: Forense Universitária; 2005. p. 62-77.

9. Campos GWS. Como reinventar a gestão e o funcionamento dos sistemas públicos e organizações estatais? Cien Saude Colet 2008; 13(Supl. 2):2019-2028.

10. Campos GWS. Saúde pública e saúde coletiva: campo e núcleo de saberes e práticas. Cien Saude Colet 2000; 5(2):219-230.

11. Nunes ED. As Ciências Sociais em Saúde: reflexões sobre as origens e a construção de um campo de conhecimento. Saúde e Sociedade 1992 1(1):59-84.

12. Nunes ED. Saúde coletiva: história de uma ideia e de um conceito. Saúde e Sociedade 1994; 3(2):5-21.

13. Nunes ED. Saúde coletiva: história e paradigmas. Interface (Botucatu) 1998; 2(3):107-116.

14. Costa NR. Ciências sociais e saúde: considerações sobre o nascimento do campo da saúde coletiva no Brasil. Saúde em Debate 1992; 36:58-65.

15. Paim JS, Almeida Filho N. Saúde coletiva: uma "nova saúde pública” ou campo aberto a novos paradigmas? Rev Saude Publica 1998; 32(4):299-316.

16. Cohn A. Conhecimento e prática em saúde coletiva: o desafio permanente. Saúde Soc 1992; 1(2):97-109.

17. Felipe JS. Uma avaliação da produção teórico-científica da medicina social no Brasil. Saúde em Debate 1989; 27:59-66.

18. Merhy EE. O capitalismo e a saúde pública. 2a ed. São Paulo: Papirus; 1987.

19. Fleury S. A análise necessária da reforma sanitária. Saúde em Debate 1998; 22:25-27.

20. Teixeira SMF. As ciências sociais em saúde no Brasil. In: Nunes ED, organizador. As ciências sociais em saúde na América Latina - Tendências e Perspectivas. Brasília: OPAS; 1985. p. 87-109.

21. Campos GWS. A saúde Pública e a defesa da vida. São Paulo: Hucitec; 1991.
22. Negri A. Opoder constituinte: ensaio sobre as alternativas da modernidade. São Paulo: DP\&A Editora; 2002.

23. Machado R, Loureiro A, Luz R, Muricy K. Danação da norma: medicina social e constituição da psiquiatria no Brasil. Rio de Janeiro: Graal; 1978.

24. Fleury S, organizador. Saúde coletiva? Questionando a onipotência do social. Rio de Janeiro: Relume-Dumará; 1992.

25. Foucault M. O nascimento da medicina social. In Foucault M. Ditos \& Escritos VII: Arte, epistemologia filosofia e história da medicina. Rio de Janeiro: Forense Universitária; 2011.p. 402-424.

26. Baremblitt G. Compêndio de análise institucional $e$ outras correntes: teoria e prática. $4^{\text {a }}$ ed. Rio de Janeiro: Record/Rosa dos Tempos; 1992.

27. Pereira JC. A explicação sociológica na medicina social [tese]. Ribeirão Preto: USP; 1983.

28. Laurell AC. A saúde-doença como processo social In: Nunes ED, organizador. Medicina social: aspectos históricos e teóricos. São Paulo: Global, 1983. p. 133-158.

29. Birman J. Jogando com a verdade: uma leitura de Foucault. Physis 2002; 12(2):301-324.

30. Birman J. Os sentidos da saúde. Physis 1999; 9(1):7-12.

31. Birman J. A interdisciplinaridade na saúde coletiva Physis 1996; 6(1/2):7-13.

32. Laurell AC. A saúde-doença como processo social In: Nunes ED, organizador. Medicina social: aspectos históricos e teóricos. São Paulo: Global; 1983. p. 133-158.

33. Berlinguer G. Uma reforma para a saúde. In: Berlinguer G, Teixeira SF, Campos GWS, organizadores. Reforma Sanitária: Itália e Brasil. São Paulo: Hucitec; 1988. p. 1-106.

34. Guattari F. Revolução molecular: pulsações políticas do desejo. 3a ed. São Paulo: Brasiliense; 1987.

35. Foucault M. A extensão social da norma. In: Foucault M. Ditos \& Escritos VII: Arte, epistemologia, filosofia $e$ história da medicina. Rio de Janeiro: Forense Universitária; 2011. p. 394-398.

36. Foucault M. A política da saúde no século XVIII. In: Foucault M. Ditos \& Escritos VII: Arte, epistemologia, filosofia e história da medicina. Rio de Janeiro: Forense Universitária; 2011. p. 357-373.

37. Foucault M. Segurança, território, população. São Paulo: Martins Fontes; 2008.

Artigo apresentado em 19/03/2014

Aprovado em 18/10/2014

Versão final apresentada em 20/10/2014 